\title{
Methodological Challenges for Epidemiologic Studies of Deprescribing at the End of Life
}

\author{
Jennifer Tjia ${ }^{1}$ (D) Jennifer L. Lund ${ }^{2}$ - Deborah S. Mack ${ }^{1}$ - Attah Mbrah ${ }^{1}$ - Yiyang Yuan ${ }^{1} \cdot$ Qiaoxi Chen ${ }^{1}$. \\ Seun Osundolire ${ }^{1} \cdot$ Cara L. McDermott $^{3}$
}

Accepted: 17 February 2021 / Published online: 23 April 2021

(C) The Author(s) 2021

\begin{abstract}
Purpose of Review To describe approaches to measuring deprescribing and associated outcomes in studies of patients approaching end of life (EOL).

Recent Findings We reviewed studies published through 2020 that evaluated deprescribing in patients with limited life expectancy and approaching EOL. Deprescribing includes reducing the number of medications, decreasing medication dose(s), and eliminating potentially inappropriate medications. Tools such as STOPPFrail, OncPal, and the Unnecessary Drug Use Measure can facilitate deprescribing. Outcome measures vary and selection of measures should align with the operationalized deprescribing definition used by study investigators.

Summary EOL deprescribing considerations include medication appropriateness in the context of patient goals for care, expected benefit from medication given life expectancy, and heightened potential for medication-related harm as death nears. Additional data are needed on how EOL deprescribing impacts patient quality of life, caregiver burden, and out-of-pocket medication-related costs to patients and caregivers. Investigators should design deprescribing studies with this information in mind.
\end{abstract}

Keywords Deprescribing $\cdot$ Medication appropriateness $\cdot$ End of life $\cdot$ Methods $\cdot$ Outcome measurement $\cdot$ Methodological

\section{Introduction}

Deprescribing is a term referring to the process of reducing inappropriate polypharmacy by discontinuing, withdrawing, or tapering medications under the direction of a healthcare provider [1]. The goal of deprescribing is to minimize potential medication risks and to achieve better patient outcomes [2].

The end of life is an important time for deprescribing, particularly for older adults, because polypharmacy is common [3-5] in the face of progressively declining organ function that

This article is part of the Topical Collection on Epidemiology of Aging

Jennifer Tjia

jennifer.tjia@umassmed.edu

1 Department of Population and Quantitative Health Sciences, University of Massachusetts Medical School, 368 Plantation Street, AS6-2065, Worcester, MA 01605, USA

2 Department of Epidemiology, UNC Gillings School of Global Public Health, UNC Chapel Hill, Chapel Hill, NC, USA

3 Division of Pulmonary, Critical Care and Sleep Medicine, University of Washington, Seattle, WA, USA increases older adults' risk of drug-related harm [6-8]. Many medications at end of life are of questionable benefit [9-11], yet most medications continue until death, while the number of end-of-life (EOL) symptom management drugs increases [5]. This changing combination of medications contributes to stress for patients and caregivers [12,13].

Studying deprescribing at end of life is important but methodologically challenging. One issue is operationalizing the definition of deprescribing. Another issue is the selection of appropriate outcome measures. Designing valid clinical trials and observational studies must balance numerous factors, including validity, utility, psychometric properties of measures, and relevance to stakeholders.

To address these challenges, we conducted this narrative review of published peer-reviewed literature to describe approaches to the measurement of deprescribing and related outcomes for studies of patients at end of life. The intention is to highlight, for a range of domains of interest to deprescribing stakeholders, what strategies have been used, whether they can be used in studies relying upon primary or secondary data collection approaches, and what may be desirable but needs further research to bring into the deprescribing toolbox. This 
paper will serve as a resource for investigators conducting studies in this growing area of research.

\section{Methods}

For this narrative review, the authors conducted a literature search in November to December 2020 of MEDLINE (PubMed), Embase, Web of Science, Google Scholar, and PsychLit for relevant empirical studies and review articles published up to December 31, 2020. Search terms included deprescribing, discontinuation, end-of-life, palliative, caregiver, outcomes, methods, and polypharmacy. We included retrospective and prospective studies conducted in humans and published in English, including observational, interventional, and cross-sectional study designs. A manual search of reference lists of included articles was performed to ensure the inclusion of relevant articles and resources. Heterogeneity across studies precluded pooling data, and herein we present results in narrative format. We first describe several methods for defining deprescribing and then organize relevant outcome measures aggregated by patient and family caregivers and into the following domains: medication-related outcomes, patientreported outcomes, clinical outcomes, safety outcomes, and cost.

\section{Results}

\section{Deprescribing}

Deprescribing includes the following: (1) drug discontinuation, (2) deintensification (i.e., gradual dose reduction without discontinuation), or (3) switching from inappropriate to appropriate drugs. Operationalizing the deprescribing definition depends on the study design, objectives, and conceptual definition of deprescribing. Observational studies may describe the prevalence of discontinuation and deintensification, while interventional studies may focus on lowering overall polypharmacy, reducing the number of inappropriate drugs, or stopping a particular class of drugs. Each of these aspects of deprescribing raise different measurement challenges.

Determination of whether discontinuation, deinten sification, or both should be included in a study can depend, in part, on the clinical recommendations for deprescribing which are specific to each drug class. Referencing drugspecific deprescribing guidelines can ensure that the more generalized definition applied (e.g., tapering vs abrupt discontinuation) represents the true prevalence of deprescribing in a population. Drug-specific recommendations for tapering vs discontinuation are emerging [14,15•]. Examples of commonly accepted recommendations for select medications appear in the Supplemental Table. For best practice, investigators may include sensitivity analyses to compare results with various deprescribing definitions.

Below we highlight approaches to operationalizing discontinuation and gradual dose reduction in observational studies.

\section{Discontinuation/Gap Periods in Drug Exposure}

One challenge to operationalizing drug discontinuation is the dynamic nature of drug prescribing, the unavailability of medical records for many studies, and the lack of explicit notation stating an unequivocal intention to stop medications when medical records are available. One general approach frequently used to define discontinuation relies on identifying gap periods in medication use. Gap periods have included 7 days [16], 14 days [17], and 30 days [18] between drug fills in published end-of-life studies based on pharmacy dispensing and claims. Non-end-of-life studies have also used 60 days [19] or 90 days [20]. Specific study examples appear in Table 1. In addition, gap periods can be determined by drugspecific pharmacokinetic properties (e.g., drug discontinuation defined as a washout period of five times the drugs halflife, representing complete excretion of the drug and biologically corresponding to an expected physiological response) [21].

\section{Deintensification and Gradual Dose Reduction}

Deprescribing may involve dose reduction without discontinuation. Defining and operationalizing gradual dose reduction is challenging because administrative claims data often lack detailed data on drug doses. Thus, operationalizing this aspect of the deprescribing approach remains largely underexplored. One important recent review [22••] highlights specific challenges, while describing innovative composite dosage intensity measures and quantified deintensification within three therapeutic classes: central nervous system agents, antihypertensives, and antidiabetic agents. Of note, each drug class required a different composite measure. For example, antihypertensive drug intensity uses defined daily dose (DDD) or maximum recommended daily dosage in the denominator. This approach has been successfully applied using hospice medication administration records in one Veterans Administration-based study [16] (Table 1).

After defining deprescribing, identifying appropriate outcome measures from the patient and caregiver perspectives is critical.

\section{Patient Outcomes}

Outcomes of interest to patients can be considered in terms of medication burden, medication-related clinical outcomes, quality of life effects, and economic impact. 
Table 1 Deprescribing measurement in end-of-life studies

\begin{tabular}{|c|c|c|c|c|}
\hline Domain & Proposed measure & $\begin{array}{l}\text { Outcome Measure Operationalization in } \\
\text { Selected Studies }\end{array}$ & Example Study with Data Source(s) & Research Gaps/Notes \\
\hline \multicolumn{5}{|c|}{ Deprescribing } \\
\hline \multirow[t]{4}{*}{ Discontinuation } & \multirow[t]{4}{*}{ Days Gap Windows } & \multicolumn{2}{|l|}{ Administrative data } & \multirow{4}{*}{$\begin{array}{l}\text { Defining discontinuation from } \\
\text { administrative data needs to } \\
\text { address how to handle restarts } \\
\text { of either the same medication } \\
\text { or medication within the same } \\
\text { class for a designated window } \\
\text { period. } \\
\text { Defining discontinuation using } \\
\text { medical records, e.g. in } \\
\text { intervention studies, is based } \\
\text { on the randomization or the } \\
\text { recorded order for } \\
\text { discontinuation and not subject } \\
\text { to inferences needed for } \\
\text { administrative data. }\end{array}$} \\
\hline & & $\begin{array}{l}\text { Operationalization: 7-day gap with 30-day } \\
\text { follow-up period }\end{array}$ & $\begin{array}{l}\text { Vu et al. } 2021 \text { (16) } \\
\text { Data: VA bar code medication administration } \\
\text { records and Minimum Data Set linked to } \\
\text { Medicare claims }\end{array}$ & \\
\hline & & $\frac{\text { Operationalization: }}{\text { follow-up period }}$ 14-day gap with 90-day & $\begin{array}{l}\text { Thorpe et al. } 2020 \text { (17) } \\
\text { Data: VA bar code medication administration } \\
\text { records and Minimum Data Set linked to } \\
\text { Medicare claims }\end{array}$ & \\
\hline & & $\begin{array}{l}\text { Operationalization: } \\
\text { follow-up period }\end{array}$ & $\begin{array}{l}\text { Mack et al. } 2020 \text { (18) } \\
\text { Data: Minimum Data Set } 3.0 \text { merged to } \\
\text { Medicare administrative claims }\end{array}$ & \\
\hline \multirow[t]{2}{*}{ Deintensification } & Gradual Dose Reduction & \multicolumn{2}{|l|}{ Administrative data } & \multirow{2}{*}{$\begin{array}{l}\text { Machine learning using } \\
\text { methods such as national } \\
\text { language processing could } \\
\text { theoretically detect explicit } \\
\text { notation of deliberate } \\
\text { deintensification/dose } \\
\text { reductions in the medical } \\
\text { records }\end{array}$} \\
\hline & $\begin{array}{l}\text { Drug class-specific strategies } \\
\text { proposed (22) } \\
\text { Central nervous system (CNS) } \\
\text { drugs - medication intensity } \\
\text { considered dividing a patient's } \\
\text { daily dose by defined daily } \\
\text { dosage (DDD), or the minimum } \\
\text { effective adult or geriatric daily } \\
\text { dosage. } \\
\text { Antihypertensive drug - } \\
\text { intensity consider either DDD } \\
\text { or maximum recommended } \\
\text { daily dosage in the } \\
\text { denominator. }\end{array}$ & $\begin{array}{l}\text { Operationalization: Dose reduction in total daily } \\
\text { dose from medication administration records for } \\
\text { at least } 7 \text { days }\end{array}$ & $\begin{array}{l}\text { Vu et al. } 2021 \text { (16) } \\
\text { Data: VA bar code medication administration } \\
\text { records and Minimum Data Set linked to } \\
\text { Medicare claims }\end{array}$ & \\
\hline
\end{tabular}

\section{Medication-Related Outcomes}

\section{Number of Medications}

Number of medications and prevalence of polypharmacy are common deprescribing outcome measures. Polypharmacy is defined as the concurrent use of multiple medications surpassing a given threshold, typically 5 ("polypharmacy") and 10 ("excessive polypharmacy"). In practice, the operationa lization of polypharmacy is inconsistent across studies in terms of the type of data available, length of measurement time, and medications counted towards "polypharmacy."

When prescription information is available in patients' complete health records, a pharmacotherapy review can provide an accurate "point prevalence" (i.e., prevalence at a particular point of time) of patients' medication use by day [23] or during the data collection period [24, 25•, 26••, 27••]. When such patient-level data is not available, linked registry databases [28••, 29•] or administrative datasets such as the Minimum Data Set [30] have been used to determine the "period prevalence" (i.e., prevalence over an interval of time) of polypharmacy. Measurement time for polypharmacy may range from "day" [23], "month" [28••, 29•], to "year" [25•].

\section{Medication Regimen Complexity}

Since medications vary in dosing frequency, a cumulative, composite measure of overall dose administration offers informative insights into drug burden beyond simple drug counts. For this purpose, the Medication Regimen Complexity Index (MRCI) [31, 32] characterizes complexity of a patient's medication regimen. MRCI weights dosage form, frequency, and administration instructions. Higher MRCI score is associated with unplanned hospitalizations [33], increased mortality [34], and nonadherence [34]. It has been used in studies of residential aged care facilities [35], palliative care interventions [36], and in a pilot trial of deprescribing in home hospice patients [ClinicalTrials.gov NCT03972163]. Implementing use in studies can be labor intensive, and efforts to automate MRCI 
calculation [37] have not yet eliminated the need for manual data entry.

\section{Medication Appropriateness}

Types of medications used are also important to consider. Determining medication appropriateness is consistent with the goal of improving the quality and safety of a patient's treatment plan. Medication appropriateness can be broadly defined using either implicit or explicit criteria. Implicit criteria are judgement-based indicators that focus primarily on the patient rather than drugs or diseases [38]. Explicit criteria are clearly defined lists of potentially inappropriate medications (PIMs). Implicit approaches tend to require time-consuming review by knowledgeable clinicians [39], thus increasing demand on investigator resources when used.

Implicit Measures For end-of-life studies, the Unnecessary Drug Use Measure defines unnecessary medications based on a simplification of the Medication Appropriateness Index. This definition includes medications that lack an indication, lack effectiveness, or are used for prolonged duration. One uncontrolled, retrospective study in geriatric palliative care simplified regimens by reducing unnecessary drug use by $65 \%$ (from 1.7 to 0.6 per patient) [ $40 \bullet$ ( Table 2).

Explicit Measures The Screening Tool of Older Persons' Prescriptions in Frail adults (STOPPFrail) was a major advance in the field. STOPPFrail, developed in 2017, is an explicit list of 27 medications that may be inappropriate in frail older adults aged 65 years or older with limited life expectancy [41]. It is based on literature review and Delphi consensus process. A study comparing the STOPPFrail to a structured geriatricianled deprescribing process (gold standard) among 100 clinical cases reported a positive predictive value of $89.3 \%$ [42]. This approach is clinically applicable and efficient, taking $3 \mathrm{~min}$ to apply when reviewing regimens of 10 drugs on average, and has high interrater reliability [42]. In a randomized controlled trial, it successfully reduced medication use [43••].

STOPPFrail version 2 was published in 2020, focusing on practicality and patient-centeredness. This version includes 25 medications and refined the definition of end of life as follows: (1) dependency in activities of daily living and/or severe chronic disease and/or terminal illness; (2) severe irreversible frailty; and (3) physician overseeing patient care would not be surprised if the patient died in the next 12 months [44••].

For cancer, OncPal was developed to aid deprescribing for patients transitioning from curative to palliative care [45•]. Based on a literature review and validated using an expert panel approach, there was excellent agreement (kappa $=0.83$ ) between OncPal and an expert panel review of drugs. Among 61 patients with a life expectancy of $<6$ months, the OncPal tool identified at least one inappropriate medication in $70 \%$ of patients.

\section{Additional Dimensions of Medication Appropriateness}

Early studies of EOL medication appropriateness broadly divided medications into symptom management and chronic disease medications [5]. While intuitively appealing, a limitation of this approach is that there is no consensus definition for either category. Studies need to tailor and redefine these categories to meet the constraints of their unique data sources [46].

More recently, medication appropriateness screening tools have sought to extend beyond dichotomous determinations of appropriate vs inappropriate. Such binary measures largely fail to consider the relevant time point of medication use (i.e., drug initiation or continuation) and the level of potential appropriateness (i.e., adequate, questionable, inadequate). Morin et al [47] sought to improve medication appropriateness tools for older adults with a life expectancy ( $<3$ months). Using a Delphi consensus panel, they identified 14 drug classes deemed "often adequate," 28 "questionable," and 10 "often inadequate" medications for continuation. For medication initiation, the panel identified 10 "often adequate," 23 "questionable," and 23 "often inadequate" drugs. In subsequent work, the authors found that in the last 3 months of life, older adults were taking approximately 9 medications, and approximately one-third continued and $14 \%$ initiated at least one drug of questionable clinical benefit [48].

\section{Goal-Concordant Prescribing}

The holy grail of care quality in end of life is goal-concordant care [49-51]. This concept is a nod to shared decision-making between clinicians and patients based on a partnership of equals [52] and focuses on the patients' goals. This is a radical departure from outdated notions of compliance and adherence that reflect whether a drug is taken according to the clinicians' orders [52]. At the end of life, goal-concordant prescribing would align medications prescribed with the patients' goals for care. Thus, reductions in overall numbers of medications or complexity may not necessarily be desirable if the overall regimen is congruent with and able to achieve stated treatment goals. While conceptually desirable to include in deprescribing studies, how to measure this remains an ongoing challenge [53].

\section{Safety}

Medication changes may result in positive or negative outcomes. Some studies use a capture of clinical events such as unplanned hospitalizations and emergency department visits to broadly measure adverse events [54, 55••] (Table 2). Inclusion of death in such measures, however, could be problematic because death is an expected in this terminally ill population. One approach used in a classic 
Table 2 Outcome measures in end-of-life deprescribing studies

\begin{tabular}{|c|c|c|c|c|}
\hline Domain & Proposed measure & $\begin{array}{l}\text { Outcome Measure Operationalization in } \\
\text { Selected Studies }\end{array}$ & Example Study with Data Source(s) & Research Gaps/Notes \\
\hline \multicolumn{5}{|c|}{ Patient Focused Measures } \\
\hline \multicolumn{5}{|c|}{ Medication-related Outcomes } \\
\hline \multicolumn{5}{|c|}{ Number of Medications } \\
\hline \multirow[t]{11}{*}{ Polypharmacy } & \multirow{11}{*}{$\begin{array}{l}\text { Conceptually defined as if the total } \\
\text { number of medications taken by a } \\
\text { patient in a given period of time } \\
\text { surpassed the pre-specified } \\
\text { threshold. } \\
\text { Thresholds commonly used are } \\
\text { (1) } 5 \text { or more medications } \\
\text { (polypharmacy) and } \\
\text { (2) } 10 \text { or more medications } \\
\text { (excessive polypharmacy). }\end{array}$} & \multicolumn{2}{|l|}{ Chart review } & \multirow{11}{*}{$\begin{array}{l}\text { Limited availability of drugs } \\
\text { included in administrative } \\
\text { dataset (Minimum Data } \\
\text { Set) } \\
\text { Inconsistency in the } \\
\text { measurement time period } \\
\text { Inconsistency in how the } \\
\text { medications were classified } \\
\text { (eg. ATC) } \\
\text { Inconsistency in the types } \\
\text { of the medications would } \\
\text { be counted towards the } \\
\text { measure of polypharmacy. } \\
\text { (e.g. chronic prescriptions } \\
\text { only or all including prn) } \\
\text { Inconsistency in the study } \\
\text { population (definition of } \\
\text { end-of -life; decedents vs } \\
\text { cohort approaching death) }\end{array}$} \\
\hline & & $\begin{array}{l}\text { Operationalization: Polypharmacy based on total } \\
\text { number of chronic drugs taken by resident for }>=6 \\
\text { months }\end{array}$ & $\begin{array}{l}\text { Molist-Brunet } 2020 \text { (96) } \\
\text { Data: Collected pharmacological data reviewed } \\
\text { through a systematic 4-stage pharmacotherapy process } \\
\text { by a multi-disciplinary team (geriatrician, nurse, clinical } \\
\text { pharmacist) }\end{array}$ & \\
\hline & & $\begin{array}{l}\text { Operationalization: Polypharmacy was defined as the } \\
\text { use of five or more prescribed chronic medications with } \\
\text { systemic effects, and excessive polypharmacy as the use } \\
\text { of ten or more. }\end{array}$ & $\begin{array}{l}\text { Paque 2019a (27) } \\
\text { Data: Medication use was based on a copy of the } \\
\text { resident's full medication chart and was evaluated two } \\
\text { times: }(t 2) \text { at the time of data collection and (t1) } \\
\text { retrospectively } 3 \text { to } 6 \text { months before. Medications were } \\
\text { classified using the Anatomical Therapeutic Chemical } \\
\text { (ATC) classification }\end{array}$ & \\
\hline & & $\begin{array}{l}\text { Operationalization: Polypharmacy was defined as the } \\
\text { use of five or more prescribed chronic medications, and } \\
\text { extreme polypharmacy as the use of ten or more. }\end{array}$ & $\begin{array}{l}\text { Paque 2019b (26) } \\
\text { Data: Medication use based on full medication charts. } \\
\text { Classified using ATC }\end{array}$ & \\
\hline & & $\begin{array}{l}\text { Operationalization: Polypharmacy was defined as } 5 \text { or } \\
\text { more medications in the last year of life }\end{array}$ & $\begin{array}{l}\text { Ho } 2020(25) \\
\text { Data: Case record review }\end{array}$ & \\
\hline & & $\begin{array}{l}\text { Operationalization: Polypharmacy defined as } 5 \text { or } \\
\text { more different drugs per day. We determined the } \\
\text { number of each prescribed medication at four } \\
\text { predefined time points: } 9 \text { (=day- }-9), 6(=\text { day }-6), 3 \\
(=\text { day- }-3 \text { ) days before death and the day of death (=day } \\
\text { 0). }\end{array}$ & $\begin{array}{l}\text { Kierner } 2016(23) \\
\text { Data: Medical charts }\end{array}$ & \\
\hline & & \multicolumn{2}{|l|}{ Linked registries } & \\
\hline & & $\begin{array}{l}\text { Operationalization: Polypharmacy based on monthly } \\
\text { exposure to } 10 \text { or more prescription drugs (authors } \\
\text { opted for the more conservative cut-off of } 10 \text { in light of } \\
\text { the chronic diseases and symptoms towards the end of } \\
\text { life), that is, distinct substances according to the fifth } \\
\text { level of the ATC classification system }\end{array}$ & $\begin{array}{l}\text { Morin et al } 2017 \text { (26) } \\
\text { Data: Nationwide study of linked registries: death } \\
\text { certificate data, Swedish prescribed drug register, social } \\
\text { services register, national patient register, Swedish } \\
\text { education register }\end{array}$ & \\
\hline & & $\begin{array}{l}\text { Operationalization: Polypharmacy based on monthly } \\
\text { use of ten or more different prescription drugs. ATC } \\
\text { classification. }\end{array}$ & $\begin{array}{l}\text { Grande } 2017 \text { (29) } \\
\text { Data: Death certificate data linked at the individual } \\
\text { level with the Swedish Prescribed Drug Register (ATC } \\
\text { classification), the National Patient Register, and the } \\
\text { Social Services Register. }\end{array}$ & \\
\hline & & \multicolumn{2}{|l|}{ Administrative dataset } & \\
\hline & & $\begin{array}{l}\text { Operationalization: polypharmacy defined as } 9+ \\
\text { medication based on the last MDS } 2.0 \text { assessment } \\
\text { before death }\end{array}$ & $\begin{array}{l}\text { Hoben } 2016 \text { (30) } \\
\text { Data: Resident Assessment Instrument-Minimum Data } \\
\text { Set } 2.0(2007-2012)\end{array}$ & \\
\hline \multicolumn{5}{|l|}{ Medication Regimen } \\
\hline \multirow{2}{*}{$\begin{array}{l}\text { Regimen } \\
\text { Complexity }\end{array}$} & \multirow{2}{*}{$\begin{array}{l}\text { Medication Regimen } \\
\text { Complexity Index (32) } \\
\\
65 \text {-item quantitative and validated } \\
\text { instrument that weights the } \\
\text { average number of medications, } \\
\text { dosage, frequency, and } \\
\text { administration }\end{array}$} & \multicolumn{2}{|l|}{ Chart review } & \multirow[b]{2}{*}{$\begin{array}{l}\text { Users manually enter the } \\
\text { dosing and route form in } \\
\text { the "automated } \mathrm{MRCl} \text { " } \\
\text { version. (37) Development } \\
\text { of a fully automated } \\
\text { version from electronic } \\
\text { medical record or } \\
\text { administrative data yet to } \\
\text { be published. }\end{array}$} \\
\hline & & $\begin{array}{l}\text { Operationalization: data entry tool available at } \\
\text { https://pharmacr.cuanschutz.edu/research/MRCTool } \\
\text { for Microsoft Access database }\end{array}$ & $\begin{array}{l}\text { Walter } 2020 \text { (36) } \\
\text { Data: Medical record review }\end{array}$ & \\
\hline \multicolumn{5}{|c|}{ Medication Appropriateness } \\
\hline \multirow[t]{3}{*}{ Explicit Criteria } & \multirow{3}{*}{$\begin{array}{l}\text { STOPP Frail V1 (41) \& } \\
\text { STOPP Frail V2 (44) } \\
\text { STOPPFrail is a list of potentially } \\
\text { inappropriate prescribing } \\
\text { indicators } \\
\text { designed to assist physicians with } \\
\text { stopping such medications in older } \\
\text { patients ( } \geq 65 \text { years) who meet ALL } \\
\text { of the criteria: } \\
\text { (1) End-stage irreversible } \\
\text { pathology; (2) Poor one year } \\
\text { survival prognosis; (3) Severe } \\
\text { functional impairment or severe }\end{array}$} & \multicolumn{2}{|l|}{ Intervention Trial } & \multirow{3}{*}{$\begin{array}{l}\text { Explicit criteria can } \\
\text { overlook importance of } \\
\text { implicit (judgement-based) } \\
\text { identification strategies } \\
\text { which can be difficult to } \\
\text { operationalize in } \\
\text { administrative data } \\
\text { Limited availability of drugs } \\
\text { included in some }\end{array}$} \\
\hline & & $\begin{array}{l}\text { Outcome measures: Primary - polypharmacy (five or } \\
\text { more drugs) at } 3 \text { months and PIMs determined by } \\
\text { medication appropriateness index (MAI). Secondary - } \\
\text { unscheduled hospital presentations, falls, quality of life, } \\
\text { monthly medication costs, and mortality. }\end{array}$ & $\begin{array}{l}\text { Curtin } 2020(43) \\
\text { Data: Case report form capture of hospital medication } \\
\text { record reviews }\end{array}$ & \\
\hline & & Chart Review & & \\
\hline
\end{tabular}




\begin{tabular}{|c|c|c|c|c|}
\hline & $\begin{array}{l}\text { cognitive impairment or both; (4) } \\
\text { Symptom control is the priority } \\
\text { rather than prevention of disease } \\
\text { progression }\end{array}$ & $\begin{array}{l}\text { Outcome measures: medication consumption was } \\
\text { determined by examining hospital Medication } \\
\text { Administration Records. Potentiallly inappropriate } \\
\text { medications were defined using STOPPFrail deprescribing } \\
\text { criteria. }\end{array}$ & $\begin{array}{l}\text { Curtin } 2018(97,98) \\
\text { Data: Medication Administration Records }\end{array}$ & $\begin{array}{l}\text { administrative datasets } \\
\text { (e.g. Minimum Data Set) } \\
\text { SToPPFrail be difficult to } \\
\text { match in an claims data not } \\
\text { supplemented with clinical } \\
\text { data to the intended } \\
\text { audience of patients who } \\
\text { meet the criteria of } \\
\text { irreversible pathology, poor } \\
\text { 1-year survival, functional } \\
\text { impairment/cognitive } \\
\text { impairment and goal of } \\
\text { symptom control }\end{array}$ \\
\hline & OncPal Deprescribing & \multicolumn{2}{|l|}{ Observational } & \multirow[b]{2}{*}{$\begin{array}{l}\text { Highly sensitive for } \\
\text { deprescribing in patients } \\
\text { with complexities such as } \\
\text { having chronic diseases } \\
\text { with different associated } \\
\text { co-morbidities or } \\
\text { multimorbidity. } \\
\\
\text { Does not include some } \\
\text { medication classes that } \\
\text { might have been identified } \\
\text { as PIM e.g., } \\
\text { antidepressants. }\end{array}$} \\
\hline & $\begin{array}{l}\text { The OncPal Deprescribing } \\
\text { Guideline was created by } \\
\text { investigating the current } \\
\text { literature for the de-escalation } \\
\text { of medications by } \\
\text { systematically reviewing each } \\
\text { medication class according to } \\
\text { the European Pharmaceutical } \\
\text { Market Research Association } \\
\text { anatomical classification list }\end{array}$ & $\begin{array}{l}\text { Measure: mean number of medications; Potentially } \\
\text { inappropriate medication defined by OncPal }\end{array}$ & $\begin{array}{l}\text { Wenedy } 2019(99) \\
\text { Data: Hospice records }\end{array}$ & \\
\hline & \multirow{2}{*}{$\begin{array}{l}\text { Preventive and Symptomatic } \\
\text { Drugs }\end{array}$} & \multicolumn{2}{|l|}{ Observational Study } & \multirow{2}{*}{$\begin{array}{l}\text { Definitions of symptomatic } \\
\text { and preventive drugs are } \\
\text { not universal and have to } \\
\text { be defined for each study. }\end{array}$} \\
\hline & & $\begin{array}{l}\text { Operationalization: Unnecessary preventive drugs and } \\
\text { symptomatic drugs defined by clinician }\end{array}$ & $\begin{array}{l}\text { Pasina } 2019 \text { (46) } \\
\text { Data: Hospice records }\end{array}$ & \\
\hline \multirow[t]{2}{*}{ Implicit Criteria } & \multirow{2}{*}{$\begin{array}{l}\text { Unnecessary Drug Use } \\
\text { Measure (3-item Medication } \\
\text { Appropriateness Index [MAI]) }\end{array}$} & \multicolumn{2}{|l|}{ Retrospective observational } & \multirow{2}{*}{$\begin{array}{l}\text { Requires manual review } \\
\text { and adjudication. }\end{array}$} \\
\hline & & $\begin{array}{l}\text { Operationalization: number of unnecessary } \\
\text { medications by } 3 \text { item MAl based on expert review }\end{array}$ & $\begin{array}{l}\text { Suhrie } 2009(40) \\
\text { Data: VA medical records }\end{array}$ & \\
\hline \multicolumn{5}{|c|}{ Safety } \\
\hline \multirow[t]{4}{*}{ Adverse Events } & $\begin{array}{l}\text { Adverse Drug Withdrawal } \\
\text { Events (ADWE) \& Adverse } \\
\text { Drug Events (ADE) }\end{array}$ & \multicolumn{2}{|l|}{ Intervention trial } & \multirow[t]{4}{*}{$\begin{array}{l}\text { There is no standardized } \\
\text { approach to defining ADWE } \\
\text { and ADE in patients at end } \\
\text { of life. }\end{array}$} \\
\hline & \multirow{3}{*}{$\begin{array}{l}\text { Approaches to identification } \\
\text { and classification typically } \\
\text { include adjudication based on } \\
\text { clinician review of data } \\
\text { abstractions }(58) \\
\text { Potential adverse events can } \\
\text { also be prespecified defined by } \\
\text { investigators }(54,55)\end{array}$} & $\begin{array}{l}\text { Operationalization: Prespecified adverse events } \\
\text { monitored at each assessment included hospital } \\
\text { admissions, emergency department visits, new } \\
\text { cardiovascular events, invasive procedures for cardiac } \\
\text { events, venous thromboembolism, and pneumonia. Ad } \\
\text { hoc adverse events were documented and monitored } \\
\text { by site investigators. }\end{array}$ & $\begin{array}{l}\text { Kutner } 2015 \text { (55) } \\
\text { Data: Medical record abstractions in intervention trial }\end{array}$ & \\
\hline & & \multicolumn{2}{|l|}{ Observational study } & \\
\hline & & $\begin{array}{l}\text { Operationalization: Potential ADE/ADWE as survival, } \\
\text { falls, fractures, hospital admissions, cognitive, physical, } \\
\text { and bowel function, quality of life, and sleep (secondary } \\
\text { outcomes) }\end{array}$ & $\begin{array}{l}\text { Potter } 2016(54) \\
\text { Data: Medical records }\end{array}$ & \\
\hline \multicolumn{5}{|c|}{ Patient Outcomes } \\
\hline \multirow{4}{*}{$\begin{array}{l}\text { Patient-Reported } \\
\text { Outcomes }\end{array}$} & \multirow[t]{2}{*}{ Quality of Life } & \multicolumn{2}{|l|}{ Intervention trial } & \multirow{4}{*}{$\begin{array}{l}\text { Relies on primary data } \\
\text { collection } \\
\text { Best used with trial } \\
\text { populations } \\
\text { Application in secondary data } \\
\text { may be possible using sources } \\
\text { such as the Minimum Data Set } \\
\text { in nursing home residents, but } \\
\text { is unexplored. }\end{array}$} \\
\hline & & $\begin{array}{l}\text { Operationalization: McGill Quality of Life (70). A } \\
\text { single-item overall QOL score and subscales (physical } \\
\text { symptom, psychological symptom, existential well- } \\
\text { being, and support) }\end{array}$ & $\begin{array}{l}\text { Kutner } 2015 \text { (55) } \\
\text { Data: Primary data collection from intervention study }\end{array}$ & \\
\hline & \multirow[t]{2}{*}{ Symptoms } & \multicolumn{2}{|l|}{ Intervention trial } & \\
\hline & & $\begin{array}{l}\text { Operationalization: Edmonton Symptom Assessment } \\
\text { Scale ( } 71) \text {. The } 9 \text { standard items on the scale (pain, } \\
\text { fatigue, nausea, depression, anxiousness, drowsiness, } \\
\text { appetite, well-being, and breathing) }\end{array}$ & $\begin{array}{l}\text { Kutner } 2015 \text { (55) } \\
\text { Data: Primary data collection from intervention study }\end{array}$ & \\
\hline \multicolumn{5}{|c|}{ Costs } \\
\hline Savings & $\begin{array}{l}\text { Potential Savings from } \\
\text { Avoiding Adverse Events }\end{array}$ & $\begin{array}{l}\text { Operationalization: Potential savings by avoiding } \\
\text { medication-related adverse events, plus reducing time } \\
\text { needed to take medications histories and perform } \\
\text { medication teaching because the patients received } \\
\text { fewer medications following deprescribing. }\end{array}$ & Not yet used in EOL deprescribing studies. & \\
\hline \multirow[t]{3}{*}{ Expenditures } & \multirow[t]{2}{*}{ Medication Costs } & \multicolumn{2}{|l|}{ Intervention trial } & \\
\hline & & $\begin{array}{l}\text { Operationalization: Calculated the } 28 \text {-day cost of } \\
\text { participants' prescription drugs using a pharmaceutical } \\
\text { wholesaler price list. For each specific medication dose } \\
\text { and formulation, the lowest cost option was chosen. }\end{array}$ & $\begin{array}{l}\text { Curtin } 2020 \text { (43) } \\
\text { Data: Medical record }\end{array}$ & \\
\hline & Patient-specific monthly cost & Intervention trial & & \\
\hline
\end{tabular}




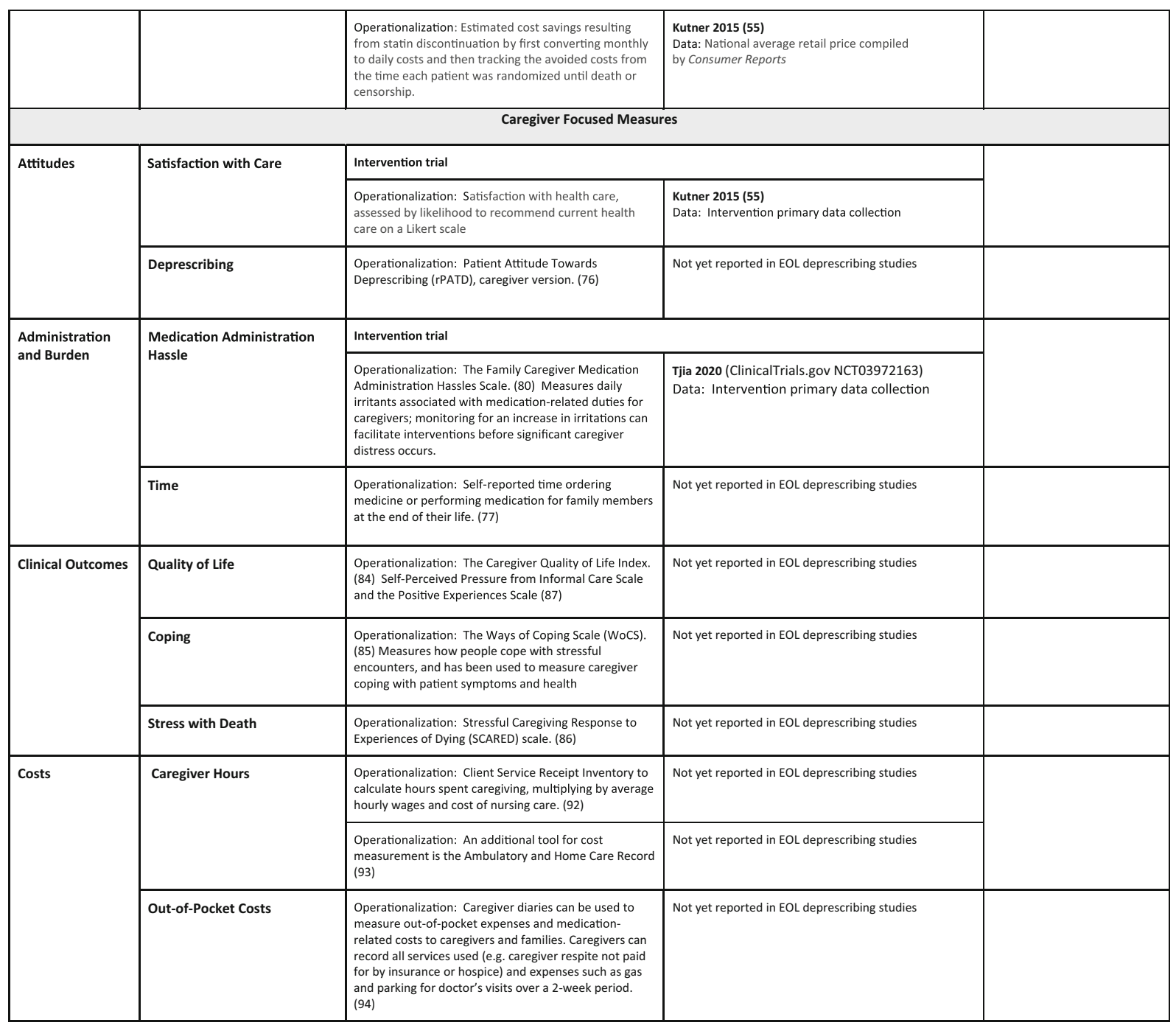

deprescribing trial was to compare occurrence of death within 60 days between discontinuation and continuation arms as evidence of safety for stopping the medication of interest $[55 \bullet \cdot]$.

More specifically, of great interest in deprescribing is the occurrence of adverse drug withdrawal events (ADWEs), defined as a "clinically significant set of symptoms or signs caused by the removal of a drug" [56]. Also of concern are adverse drug events (ADE), defined as "any injury resulting from use of a drug" including noxious or unintended drug responses at normal doses [57]. A recent review of adjudication methods to identify ADWEs and ADEs is helpful to consider when thinking about measuring these outcomes [58••]. This adjudication review summarized approaches used by clinical experts, including the following: a probability scale questionnaire [59]; a Likert-scale based measure of clinical plausibility and implied causality [60]; expert clinical judgment [61]; case assessment combining chronological, clinical, and lab findings [62]; and case assessment using a causal relationships from de-challenge and re-challenge results [63], with a version including ADE avoidability [64]. Other approaches use the following: lab tests, causality, and drug administration timing to detect unknown and unexpected adverse events [65]; patient self-report [66]; or computerized ADE monitoring [67]. Notably, distinguishing between ADWEs and ADEs remains difficult. One strategy proposes to focus on adverse event identification, and then: "Once... identified, greater focus...on determining if it represents an $\mathrm{ADE}$ or ADWE by adapting an existing framework to meet the needs identified" [58].

While not recent, it is important to note that Hanlon et al. developed an approach that can be applied to medical record 
review or patient interviews [68]. In a seminal study of ADWEs [56], medical records were screened for potential ADWE signals, including symptoms, signs, abnormal laboratory results, or clinical events known to be associated with drug withdrawal in published literature. Automation of this, and all ADE/ADWE approaches, to electronic medical records or for clinical data such as the nursing home Minimum Data Set remains a significant challenge, with exploration of natural language processing offering a promising development [69].

\section{Patient-Reported Outcomes}

Patient-reported outcomes capture aspects of end-of-life care that are important to patients and their families. Patientreported outcomes, particularly relevant to end-of-life care, include quality of life and symptom control, both physical and psychological. There are several instruments to measure these outcomes. Fortunately, the Palliative Care Research Cooperative (PCRC) group (https://palliativecareresearch. org/) has developed a measurement tool library that contains 205 relevant and high quality instruments for palliative care research as of August 2020. For each instrument, the library contains a brief instrument description, the relevant disease setting, the target respondent, and administration procedures (number of items, requirement for a trained interviewer, recall period, and average time required). The library also provides an assessment of the instrument quality and key references.

The PCRC measurement tool library contains 26 measures that assess quality of life in end-of-life settings. Some instruments are specific to a disease or condition (e.g., Alzheimer's disease, cancer), while others pertain to a given care setting (e.g., nursing home). These instruments range in time needed to complete the assessment from $5 \mathrm{~min}$ to $1 \mathrm{~h}$. One example of a high quality-rated measure includes the McGill Quality of Life Questionnaire [70], which measures four subscales including physical symptoms, psychological symptoms, outlook on life, and meaningful existence, and a single item question about physical wellbeing.

The library also includes 12 measures, all rated as high quality, assessing a range of physical symptoms, 8 of which are general measures and not disease specific. One example of a physical symptom instrument is the Edmonton Symptom Assessment System [71]. This 10-item tool assesses physical and psychosocial symptom severity and can be applied in general palliative care settings. In addition, this instrument can be completed in approximately $5 \mathrm{~min}$ by a patient or their proxy, providing additional flexibility.

Finally, the library includes 9 measures that capture psychological symptoms, with all but one being general tools for use across disease settings. These tools broadly cover measurement of depression, agitation, mood, and communication ability. One example of a psychological symptom measurement tool is the
Center for Epidemiologic Studies Depression Scale (CES-D) [72], which measures current depressive symptomatology in the past week. This 20-item instrument is one of the most widely used to measure depressive symptoms in research studies because of its excellent measurement properties, methodological quality, and consistency of results.

\section{Costs}

Cost assessment following deprescribing is rarely performed; if it is, the costs assessed are heterogeneous. Statin discontinuation among patients at end of life reduced medication costs by $\$ 3.37$ [55], using a national average retail price to calculate the avoided statin costs. A different study found significantly lower medication-related costs after deprescribing using the START/STOPP tool. Researchers counted the number of medications taken on the day of patient assessment and then summed medication costs using available price lists from the Israeli health ministry [73]. An intervention delivered to older adults with advanced cancer describes potential savings of $\$ 4200$ by avoiding ADEs, plus reducing time to take medications histories or perform medication teaching [74]. The authors assumed that each discontinued medication resulted in the avoidance of a major or minor ADE. Prices were calculated using prices established by the health system in which the study took place.

\section{Caregiver Outcomes}

Caregiver involvement is a unique aspect of end-of-life care that deserves attention in deprescribing studies, but these are largely underutilized in studies to date (Table 2). This can include measuring whether caregivers are open to deprescribing medications if a trusted clinician says stopping is possible [75]. Caregiver attitudes towards deprescribing can be assessed using the revised Patient Attitude Towards Deprescribing (rPATD) questionnaire, caregiver version [76].

\section{Medications Administration and Burden}

Caregivers play an important role in medication management for patients, from obtaining and administering medications to monitoring for symptom relief and endorsing medication use. Most caregivers report spending significant time ordering or administrating medication for family members at end of life [77]. Caregivers have described polypharmacy burden and lack of clear direction from healthcare providers as significant sources of distress when caring for a dying loved one [78]. For older adults, the degree of caregiver involvement, hospice enrollment, decedent symptom-related distress, and financial burden are associated with higher caregiver burden [79]. The 
Family Caregiver Medication Administration Hassles Scale (FCMAHS) measures daily irritants associated with medication-related duties for caregivers; monitoring for an increase in irritations can facilitate interventions before significant caregiver distress occurs [80].

\section{Clinical Outcomes}

Medication-related care may invoke anxiety among caregivers stemming from uncertainty around medication dosages and use of "as needed" medications and fear of overdosing patients, or committing medication-related errors that may shorten patient survival [81]. This may result in emergency department visits stemming from caregiver concerns about ability to manage symptoms and medications at home [82]. Factors contributing to caregiver distress include misunderstanding of pain medications, poor communication with clinicians, and inadequate knowledge of medications/assessment of pain symptoms [83]. Multiple tools are available to assess caregiver burden. The Caregiver Quality of Life Index [84] is available with multiple versions, including some specific to a particular condition such as cancer. The Ways of Coping Scale has been used to measure caregiver coping with patient symptoms and health [85]. Some caregivers report significant distress after observing patient symptoms at end of life, which can be assessed using the Stressful Caregiving Response to Experiences of Dying scale [86]. The Self-Perceived Pressure from Informal Care Scale and the Positive Experiences Scale have been used to measure caregiver burden and positive experiences stemming from providing care [87]. Other tools include the Zarit Burden Interview and the Center for Epidemiological Studies Depression Scale (CES-D) [88]. Following the loss of a patient, caregiver grief can be evaluated using the Inventory of Complicated Grief [89].

\section{Costs}

Time costs are important, as caregivers provide on average 40-70 h of care a week to patients at the end of life [90, 91]. Caregiving-related costs can be calculated by surveying individuals, then assigning costs specific to reported activity. Higginson and colleagues surveyed bereaved caregivers using the Client Service Receipt Inventory to calculate hours spent caregiving. Then, the number of hours was multiplied by average hourly wages and cost of nursing care. In the last 3 months of life, average cost to informal caregivers in the USA was $\$ 32,468$ (SD \$28,578) [92]. An additional tool for cost measurement is the Ambulatory and Home Care Record [93]. Beyond hourly time and associated wages, caregiver diaries can measure out-of-pocket expenses and medicationrelated costs to caregivers and families. For example, caregivers can record all services used (e.g., caregiver respite not paid for by insurance) and expenses such as parking for doctor's visits [94].

\section{Discussion}

This narrative review summarizes existing approaches to the measurement of deprescribing and key outcome variables for studies examining deprescribing at the end of life. For each measure, there are several approaches to consider. The selection of appropriate measure follows from the method and study design, and design follows from the research question and the investigators' vision for the study goals. Some studies implemented randomized clinical trials [43, 55], while others were observational pre-post studies $[24,40]$. Of note is the small sample size of most of the available studies. As with all epidemiological studies, the final choices depend on the details and the perspective of the stakeholders who will utilize the study results.

Since patients are central to all deprescribing studies, and the goal of deprescribing is to reduce medication burden and improve (or maintain) quality of life [1], we have summarized approaches to capturing these measures as they have been operationalized to date. Somewhat unique to EOL research is the perspective of both the patient and the caregiver. We have summarized measures including burden of medication administration and caregiver quality of life, which rely on primary data collection. While costs are important to patients and caregivers, detailed costing methods are beyond the scope of this paper. Issues such as the distinction between out-ofpocket costs vs total costs and costs versus charges are important to consider in this domain.

We suggest addressing the following issues before the application of polypharmacy as an outcome variable for deprescribing interventions in the end-of-life population.

First, identify the goal of the study and what data are available. Patient-level prescription data from medication charts can provide an accurate "point prevalence" of patients' medication use. With individualized medication history to define polypharmacy, providers could compare the drug list with medical history to initiate and follow the deprescribing process. However, such studies are limited to the end-of-life population in well-defined settings leading to limited external validity, making it difficult to validate the outcome for the deprescribing intervention and to generalize to a larger population. Alternatively, studies using registry or administrative databases can be generalized to a broader population but cannot capture the effect on individualized patient-level-deprescribing processes. Such studies can assess the medications that the patients were prescribed or dispensed, but may not reflect what the patient actually took. 
Second, identify the definition of polypharmacy. Three questions should be asked. First, what medications should be included? Although the types of medications counted towards polypharmacy are generally "chronic" medications, they may vary with regard to the specific health conditions of the end-of-life population in the study. Second, how long should medications use be measured? This depends on medication type and patients' conditions. If studies included drugs for symptom management or preventive medications in the total polypharmacy count, does the assessment time length for these drugs differ from the chronic medications that were also included? Lastly, given the baseline medication use of the study population, the common threshold of 5 or 10 medications might not be an optimal cut-off. If many medications are deprescribing targets for an end-of-life population of interest, a more conservative threshold of greater number of medications may be necessary.

For both deprescribing and outcome measures, there are differences in definitions based on whether primary data (e.g., survey) or secondary data (e.g., administrative claims or medical records) are used for assessment. Clinical outcomes such as mortality or healthcare utilization can be garnered from claims and medical records. Patient-reported outcomes such as symptom burden and quality of life are mostly reliant on primary data collection, but investigators are starting to explore methods for using secondary data sources such as the Minimum Data Set for nursing home residents. At the edge of existing methods are theoretically important outcome measures like goal-concordant prescribing that need further study for definition and operationalization from data sources. Data captured by a given resource often limits the range of variables available for inclusion. For example, there may be subtle but important differences between drug prescribing orders from medical records, drug dispensing from pharmacy records, and drug claims from administrative records.

Final selection of measures should follow from basic epidemiologic design, which requires that the investigator weigh measures based on balance of validity, reliability, feasibility, and acceptability. Feasibility and acceptability are particularly challenging in end-of-life research as primary data collection from patients who are seriously ill or dying, and their caregivers who are bereaved, is considered ethically challenging. Given these complex trade-offs, the use of a stakeholder panels can help inform study design decisions.

\section{Limitations}

Our review is limited to patient and caregiver perspectives. We did not include measures reflective of other stakeholders, including clinicians and payers [95]. Specifically, we did not review healthcare utilization measures. We focus largely on older adults in this review, which represents the available literature. We do not address the issue of how to define end-oflife, which has no widely accepted criteria to operationalize. This is an important issue for identifying the population under study and enumerating an appropriate denominator [18]. Such definitions are important to note because they affect the magnitude of the prevalence of deprescribing and medication appropriateness.

\section{Conclusion}

Deprescribing studies at EOL should consider medication types, amounts, and appropriateness in the context of patient goals of care. Additional data are needed on deprescribing at EOL in populations other than older adults. Future research should evaluate the association between deprescribing and patient quality of life, caregiver burden, and out-of-pocket medication-related costs to patients and families.

Supplementary Information The online version contains supplementary material available at https://doi.org/10.1007/s40471-021-00264-7.

Funding This study is supported by the National Institute on Aging (K24 AG068300 [JT]; R24 AG064025[JT]; R21 AG060017 [JT]; R01 AG056479 [JLL]; F99 AG068591 [YY]), National Heart Lung and Blood Institute (K12 HL137940 [CLM]), and National Center for Advancing Translational Sciences (TL1 TR001454 [DM]).

\section{Declarations}

Human and Animal Rights and Informed Consent This article does not contain any studies with humans or animals performed by any of the authors.

Conflict of Interest Dr. Tjia reports grants from National Institute of Aging during the conduct of the study. Dr. Mack reports grants from the National Institutes of Health and the National Center for Advancing Translational Sciences during the conduct of the study. Dr. Lund reports other financial activities from GlaxoSmithKline outside the submitted work. Dr. McDermott reports grants from the National Heart Lung and Blood Institute outside the submitted work. Dr. Yuan reports grants from the National Institute on Aging outside the submitted work. Ms. Chen, Dr. Mbrah, and Mr. Osundolire report no conflict of interest.

Open Access This article is licensed under a Creative Commons Attribution 4.0 International License, which permits use, sharing, adaptation, distribution and reproduction in any medium or format, as long as you give appropriate credit to the original author(s) and the source, provide a link to the Creative Commons licence, and indicate if changes were made. The images or other third party material in this article are included in the article's Creative Commons licence, unless indicated otherwise in a credit line to the material. If material is not included in the article's Creative Commons licence and your intended use is not permitted by statutory regulation or exceeds the permitted use, you will need to obtain permission directly from the copyright holder. To view a copy of this licence, visit http://creativecommons.org/licenses/by/4.0/. 


\section{References}

Papers of particular interest, published recently, have been highlighted as:

- Of importance

- Of major importance

1. Scott IA, Hilmer SN, Reeve E, Potter K, Le Couteur D, Rigby D, et al. Reducing inappropriate polypharmacy: the process of deprescribing. JAMA Intern Med. 2015;175(5):827-34.

2. Thompson W, Farrell B. Deprescribing: what is it and what does the evidence tell us? Can J Hosp Pharm. 2013;66(3):201-2.

3. McNeil MJ, Kamal AH, Kutner JS, Ritchie CS, Abernethy AP. The burden of polypharmacy in patients near the end of life. J Pain Symptom Manag. 2016;51(2):178-83.e2.

4. Dwyer LL, Lau DT, Shega JW. Medications that older adults in hospice care in the United States Take, 2007. J Am Geriatr Soc. 2015;63(11):2282-9.

5. Currow DC, Stevenson JP, Abernethy AP, Plummer J, ShelbyJames TM. Prescribing in palliative care as death approaches. J Am Geriatr Soc. 2007;55(4):590-5.

6. Zueger PM, Holmes HM, Calip GS, Qato DM, Pickard AS, Lee TA. Older Medicare beneficiaries frequently continue medications with limited benefit following hospice admission. J Gen Intern Med. 2019;34(10):2029-37.

7. Hanlon JT, Schmader KE, Koronkowski MJ, Weinberger M, Landsman PB, Samsa GP, et al. Adverse drug events in high risk older outpatients. J Am Geriatr Soc. 1997;45(8):945-8.

8. Steinman MA, Hanlon JT. Managing medications in clinically complex elders: "There's got to be a happy medium". JAMA. 2010;304(14):1592-601.

9. Riechelmann RP, Krzyzanowska MK, Zimmermann C. Futile medication use in terminally ill cancer patients. Support Care Cancer. 2009;17(6):745-8.

10. Fede A, Miranda M, Antonangelo D, Trevizan L, Schaffhausser H, Hamermesz B, et al. Use of unnecessary medications by patients with advanced cancer: cross-sectional survey. Support Care Cancer. 2011;19(9):1313-8.

11. Tjia J, Briesacher BA, Peterson D, Liu Q, Andrade SE, Mitchell SL. Use of medications of questionable benefit in advanced dementia. JAMA Intern Med. 2014;174(11):1763-71.

12. Joyce BT, Lau DT. Hospice experiences and approaches to support and assess family caregivers in managing medications for home hospice patients: a providers survey. Palliat Med. 2013;27(4): 329-38.

13. Tjia J, Ellington L, Clayton MF, Lemay C, Reblin M. Managing medications during home hospice cancer care: the needs of family caregivers. J Pain Symptom Manag. 2015;50(5):630-41.

14. Farrell B, Tsang C, Raman-Wilms L, Irving H, Conklin J, Pottie K. What are priorities for deprescribing for elderly patients? Capturing the voice of practitioners: a modified delphi process. PLoS One. 2015;10(4):e0122246-e.

15. Hanlon J, Tjia J. Avoiding adverse drug withdrawal events when stopping unnecessary medications according to the STOPPFrail Criteria. Sr Care Pharm. https://doi.org/10.4140/TCP.n.2021.136 Recent guidance on avoiding adverse drug withdrawal events when deprescribing STOPPFrail medications based on recent literature assessment.

16. Vu M, Sileanu FE, Aspinall SL, Niznik JD, Springer SP, Mor MK, et al. Antihypertensive deprescribing in older adult veterans at end of life admitted to veteran affairs nursing homes. J Am Med Dir Assoc. 2021;22(1):132-40.e5.

17. Thorpe CT, Sileanu FE, Mor MK, Zhao X, Aspinall S, Ersek M, et al. Discontinuation of statins in veterans admitted to nursing homes near the end of life. J Am Geriatr Soc. 2020;68(11):2609 19.

18. Mack DS, Baek J, Tjia J, Lapane KL. Statin discontinuation and life-limiting illness in non-skilled stay nursing homes at admission. J Am Geriatr Soc. 2020;68(12):2787-96.

19. Marcus SC, Zummo J, Pettit AR, Stoddard J, Doshi JA. Antipsychotic adherence and rehospitalization in schizophrenia patients receiving oral versus long-acting injectable antipsychotics following hospital discharge. J Manag Care Spec Pharm. 2015;21(9):754-68

20. Vinogradova Y, Coupland C, Brindle P, Hippisley-Cox J. Discontinuation and restarting in patients on statin treatment: prospective open cohort study using a primary care database. BMJ (Clinical Research ed). 2016;353:i3305-i.

21. Tjia J, Reidenberg MM, Hunnicutt JN, Paice K, Donovan JL, Kanaan A, et al. Approaches to gradual dose reduction of chronic off-label antipsychotics used for behavioral and psychological symptoms of dementia. Consult Pharm. 2015;30(10):599-611.

22.• Aspinall SL, Hanlon JT, Niznik JD, Springer SP, Thorpe CT. Deprescribing in older nursing home patients: focus on innovative composite measures for dosage deintensification. Innov Aging. 2017;1(2):igx031 Important methodologic review of approaches to measuring dosage deintensification in deprescribing studies.

23. Kierner KA, Weixler D, Masel EK, Gartner V, Watzke HH. Polypharmacy in the terminal stage of cancer. Support Care Cancer. 2016;24(5):2067-74.

24. Molist Brunet N, Sevilla-Sánchez D, Amblàs Novellas J, Codina Jané C, Gómez-Batiste X, McIntosh J, et al. Optimizing drug therapy in patients with advanced dementia: a patient-centered approach. Eur Geriatric Med. 2014;5(1):66-71.

25. Ho V, Chen C, Ho S, Hooi B, Chin LS, Merchant RA. Healthcare utilisation in the last year of life in internal medicine, young-old versus old-old. BMC Geriatr. 2020;20(1):495 Recent decedent analysis of oldest-old patients aged 80 years and older describing quality of end-of-life care, including polypharmacy as one of the many health utilization measures in the last year of life.

26.• Paque K, Elseviers M, Vander Stichele R, Dilles T, Pardon K, Deliens L, et al. Associations of potentially inappropriate medication use with four year survival of an inception cohort of nursing home residents. Arch Gerontol Geriatr. 2019;80:82-7 Inception cohort of newly admitted nursing home residents examining association between prevalence of polypharmacy and PIM use with four-year survival rate.

27.• Paque K, Elseviers M, Vander Stichele R, Pardon K, Vinkeroye C, Deliens $\mathrm{L}$, et al. Balancing medication use in nursing home residents with life-limiting disease. Eur J Clin Pharmacol. 2019;75(7): 969-77 Cross-sectional study with retrospective analyses of medication use among nursing home residents aged $\geq 65$, suffering from end stage organ failure, advanced cancer, and/or dementia $(n=296)$, with appraisal of appropriateness of medications was done using a list of medications documented as suitable for deprescribing and STOPPFrail criteria.

28.• Morin L, Vetrano DL, Rizzuto D, Calderón-Larrañaga A, Fastbom J, Johnell K. Choosing wisely? measuring the burden of medications in older adults near the end of life: nationwide, longitudinal cohort study. Am J Med. 2017;130(8):927-36.e9 Population-level analysis of data from 2007 to 2013 describing burden of medication use by older adults near end of life.

29. Grande G, Morin L, Vetrano DL, Fastbom J, Johnell K. Drug use in older adults with amyotrophic lateral sclerosis near the end of life. Drugs Aging. 2017;34(7):529-33 Nationwide retrospective cohort study of older adults who died with ALS in Sweden between 2007 and 2013. The primary outcome was the number of prescription drugs to which individuals were exposed during the last 12 months before death. 
30. Hoben M, Chamberlain SA, Knopp-Sihota JA, Poss JW, Thompson GN, Estabrooks CA. Impact of symptoms and care practices on nursing home residents at the end of life: a rating by front-line care providers. J Am Med Dir Assoc. 2016;17(2):15561.

31. Hirsch JD, Metz KR, Hosokawa PW, Libby AM. Validation of a patient-level medication regimen complexity index as a possible tool to identify patients for medication therapy management intervention. Pharmacotherapy. 2014;34(8):826-35.

32. George J, Phun YT, Bailey MJ, Kong DC, Stewart K. Development and validation of the medication regimen complexity index. Ann Pharmacother. 2004;38(9):1369-76.

33. Wimmer BC, Bell JS, Fastbom J, Wiese MD, Johnell K. Medication regimen complexity and number of medications as factors associated with unplanned hospitalizations in older people: a population-based cohort study. J Gerontol A. 2015;71(6):831-7.

34. Wimmer BC, Bell JS, Fastbom J, Wiese MD, Johnell K. Medication regimen complexity and polypharmacy as factors associated with all-cause mortality in older people: a populationbased cohort study. Ann Pharmacother. 2016;50(2):89-95.

35. Chen EY, Bell JS, Ilomaki J, Keen C, Corlis M, Hogan M, et al. Medication regimen complexity In 8 Australian residential aged care facilities: impact of age, length of stay, comorbidity, frailty, and dependence in activities of daily living. Clin Interv Aging. 2019;14:1783-95.

36. Walter KS, Gillespie H, Moqbel D, Choe HM, Smith MA. The impact of palliative care interventions on medication regimen complexity. J Palliat Med. 2020;23(2):156-7.

37. McDonald MV, Peng TR, Sridharan S, Foust JB, Kogan P, Pezzin LE, et al. Automating the medication regimen complexity index. $J$ Am Med Inform Assoc. 2013;20(3):499-505.

38. Curtin D, Gallagher PF, O'Mahony D. Explicit criteria as clinical tools to minimize inappropriate medication use and its consequences. Ther Adv Drug Saf. 2019;10:2042098619829431.

39. Spinewine A, Schmader KE, Barber N, Hughes C, Lapane KL, Swine C, et al. Appropriate prescribing in elderly people: how well can it be measured and optimised? Lancet. 2007;370(9582):17384.

40. Suhrie EM, Hanlon JT, Jaffe EJ, Sevick MA, Ruby CM, Aspinall SL. Impact of a geriatric nursing home palliative care service on unnecessary medication prescribing. Am J Geriatr Pharmacother. 2009;7(1):20-5 Observational study using Unnecessary Medication Use measure to deprescribe and reduce use of unnecessary medications in geriatric palliative care.

41. Lavan AH, Gallagher P, Parsons C, O'Mahony D. STOPPFrail (Screening tool of older persons prescriptions in frail adults with limited life expectancy): consensus validation. Age Ageing. 2017;46(4):600-7.

42. Curtin D, Dukelow T, James K, O'Donnell D, O'Mahony D, Gallagher P. Deprescribing in multi-morbid older people with polypharmacy: agreement between STOPPFrail explicit criteria and gold standard deprescribing using 100 standardized clinical cases. Eur J Clin Pharmacol. 2019;75(3):427-32.

43.• Curtin D, Jennings E, Daunt R, Curtin S, Randles M, Gallagher P, et al. Deprescribing in older people approaching end of life: a randomized controlled trial using STOPPFrail criteria. J Am Geriatr Soc. 2020;68(4):762-9 Randomized controlled trial demonstrated efficacy of a STOPPFrail guided intervention on discontinuation of PIMs among frail older adults aged 75 or older with advanced frailty and polypharmacy transitioning to long-term nursing home care.

44.• Curtin D, Gallagher P, O'Mahony D. Deprescribing in older people approaching end-of-life: development and validation of STOPPFrail version 2. Age Ageing. 2020. https://doi.org/10. 1093/ageing/afaa159 Randomized controlled trial demonstrated efficacy of a STOPPFrail guided intervention on discontinuation of PIMs among frail older adults aged 75 or older with advanced frailty and polypharmacy transitioning to long-term nursing home care.

45. Lindsay J, Dooley M, Martin J, Fay M, Kearney A, Khatun M, et al. The development and evaluation of an oncological palliative care deprescribing guideline: the 'OncPal deprescribing guideline'. Support Care Cancer. 2015;23(1):71-8 This prospective, noninterventional cohort study consisted of developing an 'OncPal Deprescribing Guideline' from current evidence, the prospective recruitment of consecutive palliative cancer inpatients with an estimated $<6$-month prognosis, the assessment of all medications to identify PIMs using both a panel of medical experts without access to the guideline as well as a Clinical Pharmacist independently using the OncPal Deprescribing Guideline and the evaluation of the guideline by testing concordance.

46. Pasina L, Recchia A, Agosti P, Nobili A, Rizzi B. Prevalence of preventive and symptomatic drug treatments in hospice care: an Italian observational study. Am J Hosp Palliat Care. 2019;36(3): 216-21.

47. Morin L, Laroche ML, Vetrano DL, Fastbom J, Johnell K. Adequate, questionable, and inadequate drug prescribing for older adults at the end of life: a European expert consensus. Eur J Clin Pharmacol. 2018;74(10):1333-42.

48. Morin L, Wastesson JW, Laroche ML, Fastbom J, Johnell K. How many older adults receive drugs of questionable clinical benefit near the end of life? A cohort study. Palliat Med. 2019;33(8):1080-90.

49. Sanders JJ, Curtis JR, Tulsky JA. Achieving goal-concordant care: a conceptual model and approach to measuring serious illness communication and its impact. J Palliat Med. 2018;21(S2):S17-s27.

50. Halpern S. Goal-concordant care - searching for the holy grail. N Engl J Med. 2019;381:1603-6.

51. Morrison SR. Advance Directives/Care Planning: Clear, Simple, and Wrong. J Palliat Med. 2020;23(7):878-9.

52. Segal JZ. "Compliance" to "concordance": a critical view. J Med Hum. 2007;28(2):81-96.

53. Sanders JJ, Miller K, Desai M, Geerse OP, Paladino J, Kavanagh J, et al. Measuring goal-concordant care: results and reflections from secondary analysis of a trial to improve serious illness communication. J Pain Symptom Manag. 2020;60(5):889-97.e2.

54. Potter K, Flicker L, Page A, Etherton-Beer C. Deprescribing in frail older people: a randomised controlled trial. PLoS One. 2016;11(3): e0149984.

55.• Kutner JS, Blatchford PJ, Taylor DH Jr, Ritchie CS, Bull JH, Fairclough DL, et al. Safety and benefit of discontinuing statin therapy in the setting of advanced, life-limiting illness: a randomized clinical trial. JAMA Intern Med. 2015;175(5):691-700 This classic study is a randomized clinical trial that provided early evidence of the net-benefits of statin discontinuation in seriously ill population with limited life expectancy. This trial has served as a model for leveraging the Palliative Care Research Cooperative Group (PCRC) to conduct clinical trials in end-oflife populations.

56. Graves T, Hanlon JT, Schmader KE, Landsman PB, Samsa GP, Pieper CF, et al. Adverse events after discontinuing medications in elderly outpatients. Arch Intern Med. 1997;157(19):2205-10.

57. Nebeker JR, Barach P, Samore MH. Clarifying adverse drug events: a clinician's guide to terminology, documentation, and reporting. Ann Intern Med. 2004;140(10):795-801.

58.• Ross C, Sydney B, Wu PE, Mc A, Anika P-FL, Tamblyn R, et al. Adverse drug events in older adults: review of adjudication methods in deprescribing studies. J Am Geriatr Soc. 2020;68(7): 1594-602 Timely and thoughtful review of aproaches to identifying adverse drug withdrawal events and adverse drug events in deprescribing studies. 
59. Naranjo CA, Busto U, Sellers EM, Sandor P, Ruiz I, Roberts EA, et al. A method for estimating the probability of adverse drug reactions. Clin Pharmacol Ther. 1981;30(2):239-45.

60. Leape LL, Bates DW, Cullen DJ, Cooper J, Demonaco HJ, Gallivan T, et al. Systems analysis of adverse drug events. ADE Prevention Study Group. JAMA. 1995;274(1):35-43.

61. Ailabouni N, Mangin D, Nishtala PS. DEFEAT-polypharmacy: deprescribing anticholinergic and sedative medicines feasibility trial in residential aged care facilities. Int J Clin Pharm. 2019;41(1): 167-78.

62. Begaud B, Evreux JC, Jouglard J, Lagier G. Imputation of the unexpected or toxic effects of drugs. Actualization of the method used in France. Therapie. 1985;40(2):111-8.

63. Karch FE, Lasagna L. Adverse drug reactions. A critical review. JAMA. 1975;234(12):1236-41.

64. Hallas J, Harvald B, Gram LF, Grodum E, Brosen K, Haghfelt T, et al. Drug related hospital admissions: the role of definitions and intensity of data collection, and the possibility of prevention. J Intern Med. 1990;228(2):83-90.

65. World Health Organization. WHO-UMC system for standardised case causality assessment. 2018. https://www.who.int/publications/ m/item/WHO-causality-assessment. Accessed 1 February 2021.

66. Baldoni Ade O, Ayres LR, Martinez EZ, Dewulf Nde L, Dos Santos V, Pereira LR. Factors associated with potentially inappropriate medications use by the elderly according to Beers criteria 2003 and 2012. Int J Clin Pharm. 2014;36(2):316-24.

67. Classen DC, Pestotnik SL, Evans RS, Burke JP. Computerized surveillance of adverse drug events in hospital patients. JAMA. 1991;266(20):2847-51.

68. Hanlon JT, Pieper CF, Hajjar ER, Sloane RJ, Lindblad CI, Ruby $\mathrm{CM}$, et al. Incidence and predictors of all and preventable adverse drug reactions in frail elderly persons after hospital stay. J Gerontol A Biol Sci Med Sci. 2006;61(5):511-5.

69. Jagannatha A, Liu F, Liu W, Yu H. Overview of the first natural language processing challenge for extracting medication, indication, and adverse drug events from electronic health record notes (MADE 1.0). Drug Saf. 2019;42(1):99-111.

70. Cohen SR, Mount BM, Strobel MG, Bui F. The McGill Quality of Life Questionnaire: a measure of quality of life appropriate for people with advanced disease. A preliminary study of validity and acceptability. Palliat Med. 1995;9(3):207-19.

71. Bruera E, Kuehn N, Miller MJ, Selmser P, Macmillan K. The Edmonton symptom assessment system (ESAS): a simple method for the assessment of palliative care patients. J Palliat Care. 1991;7(2):6-9.

72. Radloff L. The CES-D scale: a self-report depression scale for research in the general population. Appl Psychol Meas. 1977;1(3): 385-401.

73. Frankenthal D, Israeli A, Caraco Y, Lerman Y, Kalendaryev E, Zandman-Goddard $\mathrm{G}$, et al. Long-term outcomes of medication intervention using the screening tool of older persons potentially inappropriate prescriptions screening tool to alert doctors to right treatment criteria. J Am Geriatr Soc. 2017;65(2):e33-e8.

74. Whitman A, DeGregory K, Morris A, Mohile S, Ramsdale E. Pharmacist-led medication assessment and deprescribing intervention for older adults with cancer and polypharmacy: a pilot study. Support Care Cancer. 2018;26(12):4105-13.

75. Reeve E, Low LF, Hilmer SN. Attitudes of older adults and caregivers in Australia toward deprescribing. J Am Geriatr Soc. 2019;67(6):1204-10.

76. Reeve E, Low LF, Shakib S, Hilmer SN. Development and validation of the revised patients' attitudes towards deprescribing (rPATD) questionnaire: versions for older adults and caregivers. Drugs Aging. 2016;33(12):913-28
77. Ornstein KA, Kelley AS, Bollens-Lund E, Wolff JL. A National profile of end-of-life caregiving in the United States. Health Aff (Millwood). 2017;36(7):1184-92.

78. Sheehy-Skeffington B, McLean S, Bramwell M, O'Leary N, O'Gorman A. Caregivers experiences of managing medications for palliative care patients at the end of life: a qualitative study. Am J Hosp Palliat Care. 2014;31(2):148-54.

79. Tilden VP, Tolle SW, Drach LL, Perrin NA. Out-of-hospital death: advance care planning, decedent symptoms, and caregiver burden. J Am Geriatr Soc. 2004;52(4):532-9.

80. Travis SS, Bernard MA, McAuley WJ, Thornton M, Kole T. Development of the family caregiver medication administration hassles scale. Gerontologist. 2003;43(3):360-8.

81. Payne S, Turner M, Seamark D, Thomas C, Brearley S, Wang X, et al. Managing end of life medications at home-accounts of bereaved family carers: a qualitative interview study. BMJ Support Palliat Care. 2015;5(2):181-8.

82. Smith AK, Schonberg MA, Fisher J, Pallin DJ, Block SD, Forrow L, et al. Emergency department experiences of acutely symptomatic patients with terminal illness and their family caregivers. J Pain Symptom Manag. 2010;39(6):972-81.

83. Chi NC, Demiris G. Family caregivers' pain management in end-oflife care: a systematic review. Am J Hosp Palliat Care. 2017;34(5): 470-85.

84. Weitzner MA, Jacobsen PB, Wagner H Jr, Friedland J, Cox C. The caregiver quality of life index-cancer (CQOLC) scale: development and validation of an instrument to measure quality of life of the family caregiver of patients with cancer. Qual Life Res. 1999;8(12):55-63.

85. Washington KT, Wilkes CM, Rakes CR, Otten SJ, Parker Oliver D, Demiris G. Relationships among symptom management burden, coping responses, and caregiver psychological distress at end of life. J Palliat Med. 2018;21(9):1234-41.

86. Luth EA, Maciejewski PK, Phongtankuel V, Xu J, Prigerson HG. Associations Between Hospice Care and Scary Family Caregiver Experiences. J Pain Symptom Manage. 2020. https://doi.org/10. 1016/j.jpainsymman.2020.08.041.

87. Boogaard JA, van der Steen JT, de Boer AH, van Groenou MIB. How is end-of-life care with and without dementia associated with informal caregivers' outcomes? Am J Hosp Palliat Care. 2019;36(11):1008-15.

88. Tsai CF, Lee YT, Lee WJ, Hwang JP, Wang SJ, Fuh JL. Depression of family caregivers is associated with disagreements on lifesustaining preferences for treating patients with dementia. PLoS One. 2015;10(7):e0133711.

89. Prigerson HG, Maciejewski PK, Reynolds CF 3rd, Bierhals AJ, Newsom JT, Fasiczka A, et al. Inventory of complicated grief: a scale to measure maladaptive symptoms of loss. Psychiatry Res. 1995;59(1-2):65-79.

90. Rowland C, Hanratty B, Pilling M, van den Berg B, Grande G. The contributions of family care-givers at end of life: a national postbereavement census survey of cancer carers' hours of care and expenditures. Palliat Med. 2017;31(4):346-55.

91. Wolff JL, Dy SM, Frick KD, Kasper JD. End-of-life care: findings from a national survey of informal caregivers. Arch Intern Med. 2007;167(1):40-6.

92. Higginson IJ, Yi D, Johnston BM, Ryan K, McQuillan R, Selman $\mathrm{L}$, et al. Associations between informal care costs, care quality, carer rewards, burden and subsequent grief: the international, access, rights and empowerment mortality follow-back study of the last 3 months of life (IARE I study). BMC Med. 2020;18(1):344.

93. Guerriere DN, Coyte PC. The ambulatory and home care record: a methodological framework for economic analyses in end-of-life care. J Aging Res. 2011;2011:374237. 
94. Essue BM, Beaton A, Hull C, Belfrage J, Thompson S, Meachen $\mathrm{M}$, et al. Living with economic hardship at the end of life. BMJ Support Palliat Care. 2015;5(2):129-37.

95. Parekh N, Schenker Y, Good CB, Neilson L, Shrank WH. Deprescribing in advanced illness: aligning patient, clinician, and health plan goals. J Gen Intern Med. 2019;34(4):631-3.

96. Molist-Brunet N, Sevilla-Sánchez D, González-Bueno J, GarciaSánchez V, Segura-Martín LA, Codina-Jané C, et al. Therapeutic optimization through goal-oriented prescription in nursing homes. Int $\mathrm{J}$ Clin Pharm. 2020. https://doi.org/10.1007/s11096-020-01206-x.

97. Curtin D, O'Mahony D, Gallagher P. Erratum: Drug consumption and futile medication prescribing in the last year of life: an observational study. Age Ageing. 2018;47(5):749-53.
98. Curtin D, O'Mahony D, Gallagher P. Drug consumption and futile medication prescribing in the last year of life: an observational study. Age Ageing. 2018;47(5):749-53.

99. Wenedy A, Lim YQ, Lin Ronggui CK, Koh GCH, Chong PH, Chew LST. A study of medication use of cancer and non-cancer patients in home hospice care in Singapore: a retrospective study from 2011 to 2015. J Palliat Med. 2019;22(10):1243-51.

Publisher's Note Springer Nature remains neutral with regard to jurisdictional claims in published maps and institutional affiliations. 